\title{
Improvement of Ability and Creativity in Pre-School Children
}

\author{
Mamatov Dilshod
}

\begin{abstract}
The purpose is to develop the competencies of teaching and practicing knowledge of the formation of pictorial activities in preschools.

- to know and apply the types, methods of teaching of visual activity;

- development of visual abilities and creativity of preschool children;

- development of skills of using modern technologies of shaping the pictorial activity in preschool children.
\end{abstract}

Keywords : preschool education, high qualification, methods, artistic taste, creative thinking and imagination, perception, aesthetic sensations.

\section{INTRODUCTION}

$\mathrm{P}_{\text {sychologists, educators and art historians have been }}$ instrumental in propagating the content and original structure of the graphic arts program, its pedagogical and advanced practice, and the development of techniques for visual art. In particular, A.V.Bakushinsky, E.A.Flerina, K.M.Apilov, N.T.Sakulina and other scholars.

\section{LITERATURE REVIEW}

R. Hasanov, V.A.Ezekeeva, O.Sukhareva, K.Kosimov and others, who have done scientific research on Uzbek folk art and sculpture, and E.Flerina, N.A.Vetlugina,T.S.Komarova, E.Umarov, R.Karimov, M.Mirsaidova, G.Oyxujayeva and others have emphasized in their research work that children's creativity should be developed in educational process.

\section{MAIN PART}

If Years of observations and studies help children to master elementary ways of making toys, both in and out of classes, working together to help children develop the skills they need, to increase their creative potential, to help prepare them for school education.

Radical improvement of the level of preparation of children for school education by implementing the Decree of the President of the Republic of Uzbekistan dated December 29, 2016 № PP-2707 "On measures to further improvement of the system of preschool education in 2017-2021", introduction of modern educational programs into the

Revised Manuscript Received on October 15, 2019.

* Correspondence Author

Mamatov Dilshod*, Associate Professor of Bukhara State University (Uzbekistan), dilshod555ts@mail.ru educational process, provision of qualified pedagogical staff, creation of conditions for comprehensive intellectual, moral, aesthetic and physical development of children, material and technical base of educational institutions. The action plan for the further improvement of the education system for 2017-2021 has been developed.

The mission of preschool education is to educate children in the rich national, cultural and historical heritage and moral ethics of the people: to form a sense of national patriotism in children, to formulate the need for education, the desire for learning in preschool children and prepare them for regular education. The development of children's thinking, the ability to express themselves freely and freely, and the physical and mental health of children. One of the main objectives of the modern art is to identify and develop the skills and abilities of children in modern art.

The challenge is to educate educators who can understand the complexities of the fine arts and have the ability to share its subtle details with preschool children.

The role of the educator in shaping the aesthetic abilities of children through prescriptive activities in preschools is invaluable. He has to have deep knowledge and high qualification, constantly work on himself, constantly improve his theoretical level, and rely on advanced experience.

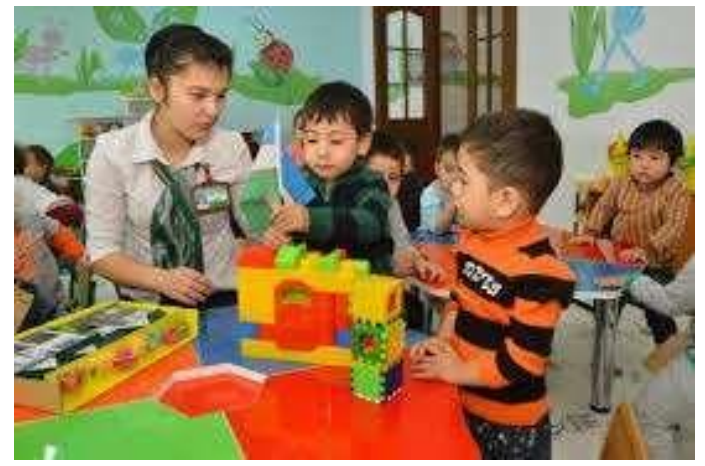

The State National Program is aimed at radical reforming of the education system, its adaptation in form and content, and continuous improvement of the quality of education.

The pre-school program of fine arts and the school's fine arts program involves the development of creative abilities and images of children to develop aesthetic attitude to the environment. During pre-school activities, the tasks required for successful schooling are addressed. In the process of drawing, applause, diarrhea, the children form the analysis, synthesis, repetition, concrete. 
Children also learn how to work in a team, to put their actions into action by their friends. Visual activities in the preschool form the skills that children need in their educational activities.

Primary artistic activity of preschool educational institutions is the artistic aesthetic education of preschool children.

\section{RESEARCH AND ANALYSIS}

Before The effectiveness of this direction becomes clear only when the complex of all aesthetic means (theater, music, fiction, drawing, applause, etc.) is used. The "Visual Activity" classes in preschools are important for solving aesthetic issues for children. Because the artistic activity is by its very nature an artistic activity. All types of artistic activities provide a great opportunity for children to learn about beauty and to develop an emotional and aesthetic attitude to all things.

During the "Visual Activity" classes:

1. Teaching artistic taste;

2. Development of applied art activities and skills;

3. Development of fantasy, creative thinking and imagination, perception;

4. Development of hand motions and fine motor motions;

5. Educational and upbringing issues, such as creating opportunities for professional and creative activity to be demonstrated.

An analysis of the structure and content of the improved Bolajon support program for preschools reveals that most of the time, from small groups, has been devoted to visual activity.

Types of pictorial activities:

- photo ( 2 hours)

- Application (0.5 hours)

- drying (0.5 hours)

- Total projection is 4 hours, including projection (1 hour).

Given that the weekly load is 12 hours, visual activity accounts for one-third of all activities.

Consequently, the pictorial activity is the largest unit of integrative content and is logically and didactically related to other activities. This means that the content and methodology of the pictorial activity should be improved in harmony with other activities.

Children in pre-school education are mainly engaged in visual work, painting with artwork; and at school, the types of fine arts become more familiar with painting, graphic, sculpture and decorative arts. There are a variety of activities in the pre-school: painting, clay, applique, building and finishing.

All pre-school activities are very important. Successful resolution of educational issues in the elementary grades is closely linked with the training in pre-school education.

Children will be taught how to control their character and hands during group activities and free access to pencils and paintings. It promotes skill acquisition, the ability of children to move their arms with ease and free movement. Children learn to navigate according to the nature of the subject, and to move according to the size of the subject when drawing different shapes, sizes and proportions. In preschool activities, they are taught to use the material in an orderly manner, to keep it clean, and to plan only the necessary materials and how to use it. This activity will help children develop attention and vision.

In the pre-school preparation group, the requirements for drawing or drawing based on the nature of the curriculum increase, and these requirements are closer to school requirements. Illustrative illustration of the sequence of work is done only at the initial stage of preparation and training of children in a large group. Children attempt to analyze the whole picture on a paper, compare the image to the image, correct the errors and deficiencies, and make the image look natural.

Discovering and visualizing geometric shapes in visual activity classes, using terms, width, height, height, and spatial positioning of the parts help children to master elementary mathematical concepts in school.

Building materials from the construction classes will help children develop eye-catching skills and help children master or master the technical lessons in school. As a result, children acquire artistic abilities and creative abilities in the classroom. Because children are inextricably linked to objects, they are familiar with their specific qualities, shapes, colors and sizes, identify their differences and similarities, which allow children to develop sensory, visual, and reflective thinking.

Visual activities educate children. Children reflect on events in their lives and in society, and they are excited. In the process of visual activity, children are taught the qualities of the will - the goal of completing the work, the desire to do it, the overcoming of difficulties and the help of their comrades. Helping children, teamwork in team building work; in the process of evaluating a case, they form moral qualities, such as the actual attitude of their comrades to the work, the proper evaluation, the satisfaction of their work and their comrades. Visual activity is an activity that encourages children to work hard to achieve their goals. Visual activity is the main tool for aesthetic education of children.

The separation of each object's size, color, shape, and space is part of the aesthetic sense. The development of aesthetic sensations in children is associated with a deeper sense of color, rhythm, and proportion. When a child senses color, form, and diversity, the more he or she enjoys the diversity of colors becomes. The development of aesthetics in children develops aesthetic evaluation of the subject and some of its qualities. They instill in them an understanding of the works of fine art, their feelings and attitudes. Visual activities play an important role in children's artistic growth. The artistic growth of a child is the acquisition of figurative thinking, aesthetic perception, and the skills needed to create an image. 


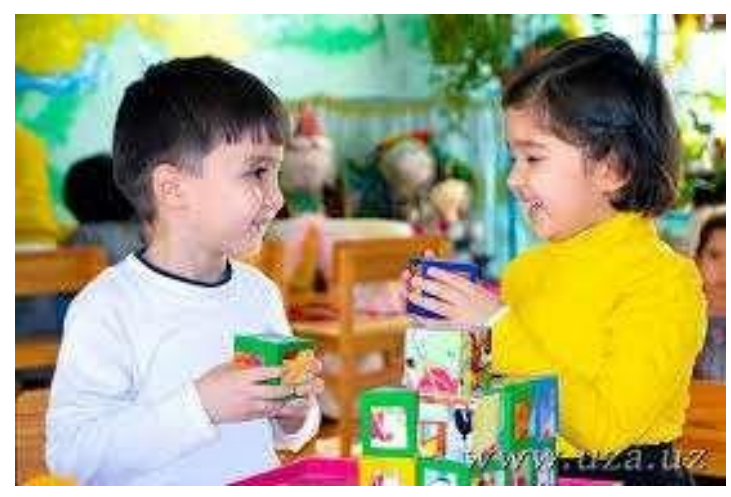

For example, take a walk in the nature or amusement park, take a fall tour. Educating children can be cultivated by the aesthetic sense that comes from observing the subject or the environment, such as the proper appreciation of the environment, human labor, and love for the country. The main task of artistic and ethical education is to create children to do their job beautifully and well, to be liked and liked by others.

\section{CONCLUSION}

In summary, illustrative activities are very important in the preparation of preschool children. Acquiring knowledge and skills in painting, clay, and building materials is the key to successful schoolwork and work classes.

It prepares them for educational activities: teaches them to listen to the teacher and follow his instructions. One of the main reasons for this educational activity is to find out the main and important ways to solve the task. They also play a role in overseeing their work in school. The child is also psychologically prepared during the pictorial activity.

\section{REFERENCES}

1. "State Preschool Requirements" T: 2017

2. Bolajon Support Program. T .: 2016

3. Ishmukhamedov R.J., Yuldashev M. Innovative pedagogical technologies in education and training. 2016

4. Tolipov O., Usmanbayeva M. Introduction principles of pedagogical technologies T: 2006. - 163

5. Ishmuhamedov R. Methods of using interactive methods and pedagogical technologies in the learning process. T : RBIMM, 2008. $68 \mathrm{p}$.

6. Z. Ibragimova, Fiction in Preschool. (first, small, medium, large and preparatory group exercises) .T., 2012.

7. Ibragimova Z. Fiction collection under the "Bolajon" support program. Book 1., T., 2013.

8. Professional Development Institutions: http://www.pedagog.uz

9. Iste'dod Foundation: http://www.istedod.uz

10. Republican Children's Library: www.kitob.uz

11. Social Information Education Portal: www.ziyonet.uz 